\title{
THE IMPACT OF OCCUPATIONAL HEALTH AND SAFETY (OH\&S) MANAGEMENT Systems ON Risk MANAgEMENT PraCTiCES
}

\author{
Srđan Vulanović, Marina Žižakov, Stana Vasić, Milan Delić \& Nemanja Sremčev
}
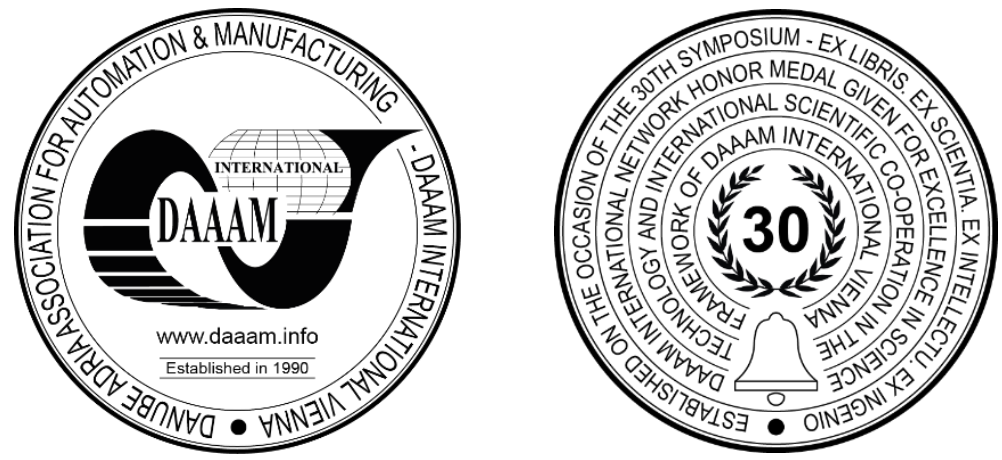

This Publication has to be referred as: Vulanovic, S[rdjan]; Zizakov, M[arina]; Vasic, S[tana]; Delic, M[ilan] \& Sremcev, N[emanja] (2019). The Impact of Occupational Health and Safety (OH\&S) Management Systems on Risk Management Practices , Proceedings of the 30th DAAAM International Symposium, pp.1188-1195, B. Katalinic (Ed.), Published by DAAAM International, ISBN 978-3-902734-22-8, ISSN 1726-9679, Vienna, Austria DOI: $10.2507 / 30$ th.daaam.proceedings.167

\begin{abstract}
This study examines the relationship between the key practices of occupational health and safety management systems (OHSMS) and occupational health and safety risk management practices (OHSRMP). For the research purposes, the authors have elaborated the theoretical constitution of research dimensions and research model was developed, in accordance with relevant literature sources. This study was based on a questionnaire as a research instrument. The key dimensions were operationalised with 47 manifest variables, within seven dimensions of OHSMS (i.e. leadership, employee involvement, work environment, stress management and OHS training) and one higher-order dimension of OHSRMP. The study was conducted in Serbia. The sample was consisted of 116 organisations, from various industry sectors. The research model was found to be valid and reliable. In order to examine the impact of the predictors variables, multiple linear regression was performed, using Minitab software. The results show that the relationship between leadership and risk management is not statistically significant, whereas the other predictor variables are proved to have strong statistically significant positive impact. OHS training has the greatest positive influence on risk management, which is known to be one of the most important practices in effective OHSMS.
\end{abstract}

Keywords: OHSMS; Risk management; Linear regression; Stress management

\section{Introduction}

Many studies have recognised the important role played by the organisations management in reducing accidents [1], [2], [3] because of that, accidents have adverse effects in terms of productivity and quality decreasements, deterioration of the organisations public image and internal climate [4]. What this tells us is that actions on managing risks that lead to any kind of damage to the health of employees. Therefore, factors that have a strong impact on risk management should be explored. Thus, many authors have already established numerous factors that have a strong influence on OH\&SMS, including: (1) leadership, (2) employee involvement, (3) work environment, (4) stress management and (5) OHS training [5].

With this paper the authors intend to point to a direct link between these factors, listed above; and risk management. The goal is to examine the nature of these relationships and to define factors which have the greatest influence on risk 
management. This means that the future investments could be focused on improving the most influential factor, which, consequently, leads to improving risk management.

\section{Theoretical background}

Based on the literature review, it can be argued that, OHSMS is measured with five factors. These are: (1) Leadership, (2) Employee participation, (3) Work environment, (4) OHS training, (5) OHS risk management [6], [7], [8]. Accordingly, Vulanovic et al 2019., have stated that stress is strongly connected to OHSMS factors and organisational performance. Consequently, in this paper, stress management will also be analysed as an influential factor.

\section{Leadership}

Human resources are the most important factors for effectiveness and efficiency in organisations [9]. One of the main elements of quality management and OHS is the role of managers in practicing leadership. [10]; [11]; [12]

Leadership is what fosters unity between leader and organisation. The leader sets OHS and other goals to match the vision of the organisation, where the goals are formulated to achieve better capabilities for the adoption of change [13]. Organisations need effective managers and employees to achieve their objectives. [9] Additionally, the necessary resources and training should be given to employees by top management [13]. Without full commitment of top management (i.e. leadership), there is no effective functioning of any system.

\section{Employee involvement}

Participation of the employees in health and safety activities is studied in several references and aimed at promoting safe behaviour and involving personnel in decision-making processes [14]. Employee involvement is one of the seven QMS principles [5]. This principle leads to empowering people in the organisation by giving them more responsibility, so that they understand that their contribution and their role in the organisation is important [9].

Employees should be actively involved in risk management processes linked to their workplace. Takin in consideration they are best familiar with their everyday activities, they can easily identify the risks. Most importantly, this makes them capable to act preventive or better said, minimize the risks in everyday activities[15].

\section{Work environment}

The working environment is the place where the work is carried out and includes jobs, working conditions, working procedures and relationships in the work process [5]. The quality of the employees' workplace environment most impacts on their level of motivation, performance, but it also leads to injuries [16]. Working conditions include are: microclimate, chemical harm, physical harm, lighting and biological harm, where all of this should be controlled every 3 years [17]. For example, workplace noise can very much influence the level of concentration, ear damage and psychic condition. Also, the vibrations can cause nausea and discomfort. What this tells us is that working in non-adequate environment effects health condition of the employees on a high level [18].

\section{Training}

In accordance with the law, employees must undergo compulsory training in order to be competent to carry out their work in the workplace [17]. In addition, employees must be trained in risk assessment at their workplace. Training and development of employee competences, in order to improve ability, skills, and aptitudes in terms of risk prevention, is one of the most important practices OHSMS [14].

\section{Stress management}

Estimates suggest that roughly 91.5 million working days are lost each year through stress-related illness. Respectively, half of all work absences are due to work-related stress disorders [19], [20], [21].

The amount of work hours for employees is directly connected to the amount of caused stress. Moreover, this leads to: reduced efficiency, reduced capacity to perform, reduced interest in working, increased rigidity of thought, lack of concern for the organisation and colleagues and loss of responsibility. Needless to say, the possibility for work injuries is increased. With this said, it is necessary to manage stress in order to control its consequences [18].

\section{Risk management}

Risk is the potential for a negative future reality that may or may not happen [34]. The focus of ISO standards is on prevention. Preventive action is being replaced with risk-based thinking [22]. When planning for the OH\&S management system, the organisation shall determine the risks and opportunities that need to be addressed to give assurance that the OH\&S management system can achieve its intended outcomes; prevent, or reduce undesired effects and achieve continual improvement. In ISO 45001, risk is defined as the combination of the likelihood of an occurrence of a hazardous event and the severity of injury that can be caused [23]. Elimination of health and safety risks is the ultimate goal of an effective OHSMS. All of the risks and their consequences must be assessed and adequately treated. This is the reason why secondorder constructs were established to describe risk management. These are: (1) Incidents, (2) Emergency situations and (3) Risk assessment and measures. 
With the literature review, it is established that all the factors are connected to risk management; and in accordance with the aim of the research, the hypothesis stated in the following text can be defined as:

Hypothesis 1: Leadership has positive impact on risk management

Hypothesis 2: Employee involvement has positive impact on risk management

Hypothesis 3: Work environment has positive impact on risk management

Hypothesis 4: OHS training has positive impact on risk management

Hypothesis 5: Stress management has positive impact on risk management

\section{Materials}

\subsection{The research instruments}

The questionnaire, that was used as a research instrument in this study, had 47 manifest variables relating to relevant constructs. The questionnaire was defined by the authors of this paper. The study was conducted in 116 companies in Serbia. The research model was empirically tested and was found to be valid and reliable. The questionnaire was distributed electronically and manually to 446 companies (just over $50 \%$ of the assessed number of existing certified organisations situated in Serbia). With this said, it is clear that the number of organisations that the questionnaire was distributed to is limited by the condition of their certification. The number of certified organisations in Serbia is not on a high level. Also, the financial indicators are excluded due to the lack of information the respondents are willing to share in this field. After the 3 months period, responses were obtained from 166 respondents. However, only 116 correctly filled questionnaires were taken into the consideration and analysed, leading to a total of $26 \%$ response rate. To capture the respondents subjective estimates about the statements, a five pointunipolar Likert type scale was used [33].

In the first section, out of 8 sections the questionnaire is structured in, respondents gave background information about themselves and their organisations. In the next sections, the construct of OHS was operationalized with a total of 32 manifest variables. According to the relevant literature sources, Occupational health and safety was operationalized with: (1) Leadership (6 manifest variables), (2) Employee involvement (5 manifest variables), (3) Work environment (6 manifest variables), (4) Training (5 manifest variables) and (5) Risk management (14 manifest variables). The Risk management itself, as a second order construct, was composed of: (1) Incidents (5 manifest variables), (2) Emergency situations (4 manifest variables) and (3) Risk assessment and measures (5 manifest variables). In the seventh and eight sections two more constructs were added: (1) Stress management (5 manifest variables) and (2) Occupational health and safety performance (6 manifest variables). All statements used as manifest variables were affirmative, for listed constructs.

\subsection{Data collection and sample}

Due to the lack of information, it can only be assumed that the number of OHSAS 18001/ISO 45001 certified companies in Serbia is close to the number of ISO 14001 certified organisations. OHSAS 18001/ISO 45001 standard is almost, word-for-word, identical to the ISO 14001 standard, excluding the specific terminology used in each standard. Moreover, the authors of this paper have a lot of experience with consulting services in Serbia and region, concerning the implementation of management standards requirements. Based on their knowledge, prevalent number of organisations aim for the integrated implementation of both standards.

\subsection{Sample demographics}

The sample is consisted of 116 safety officers (i.e. organisations). Most of them were males (74, 63.8\%), followed by the less frequent female respondents $(42,36.2 \%)$. Further, all types of age groups were included into study design. Consequently, $18(15.5 \%)$ respondents were below the age of 30, $32(27.6 \%)$ of them were between the age of 31 and 40 , $41(35.3 \%)$ respondents fell into the age category between 41 and 50, while $21(18.1 \%)$ respondents were older than 51 . Only a small fraction of respondents failed to provide this data $(4,3.4 \%)$. Roughly, equal number of respondents comes from production $(36,31 \%)$, service $(46,39.7 \%)$ and production/service $(34,29.3 \%)$ types of organisations. The number of large $(39,33.6 \%)$, medium $(29,25 \%)$, small $(23,19.8 \%)$ and micro $(24,20.7 \%)$ organisations were also roughly equally included into the sample, with only small number of missing data $(1,0.9 \%)$. Most of the 116 respondents come from the industrial sector, followed by the mining and energetics (Table 1). 


\begin{tabular}{|l|r|r|}
\hline Sector & $\mathrm{N}$ & $\%$ \\
\hline Industrials & 61 & 52.6 \\
\hline Agriculture & 1 & 0.9 \\
\hline Mining and energetics & 10 & 8.6 \\
\hline Traffic and transport & 9 & 7.8 \\
\hline Public utilities & 9 & 7.8 \\
\hline Trade and commerce & 9 & 7.8 \\
\hline Tourism & 2 & 1.7 \\
\hline Chemicals and pharmacy & 3 & 2.6 \\
\hline Insurance & 2 & 1.7 \\
\hline Education & 3 & 2.6 \\
\hline Culture and sport & 1 & 0.9 \\
\hline IT & 1 & 0.9 \\
\hline Healthcare & 5 & 4.3 \\
\hline Total & 116 & 100.0 \\
\hline
\end{tabular}

Table 1. Sample demographics by industry sectors

It can be seen that, from these answers, most of the respondents are dealing with some type of stress, whether it comes from increased risk of injury, formal system sanctions or the lack of employee motivation towards the development of OHS.

Moreover, such responses provide rationale towards the inclusion of SM, as an integral part of OHS. This was mostly not the case in previous studies.

\section{Methods}

In order to examine the impact of the OHS key dimensions (i.e. (1) Leadership, (2) Employee involvement, (3) Work environment, (4) OHS training and (5) Stress management) on the risk management, a multiple linear regression analysis was performed, using Minitab software 17.1. The research model is shown on Fig. 1.

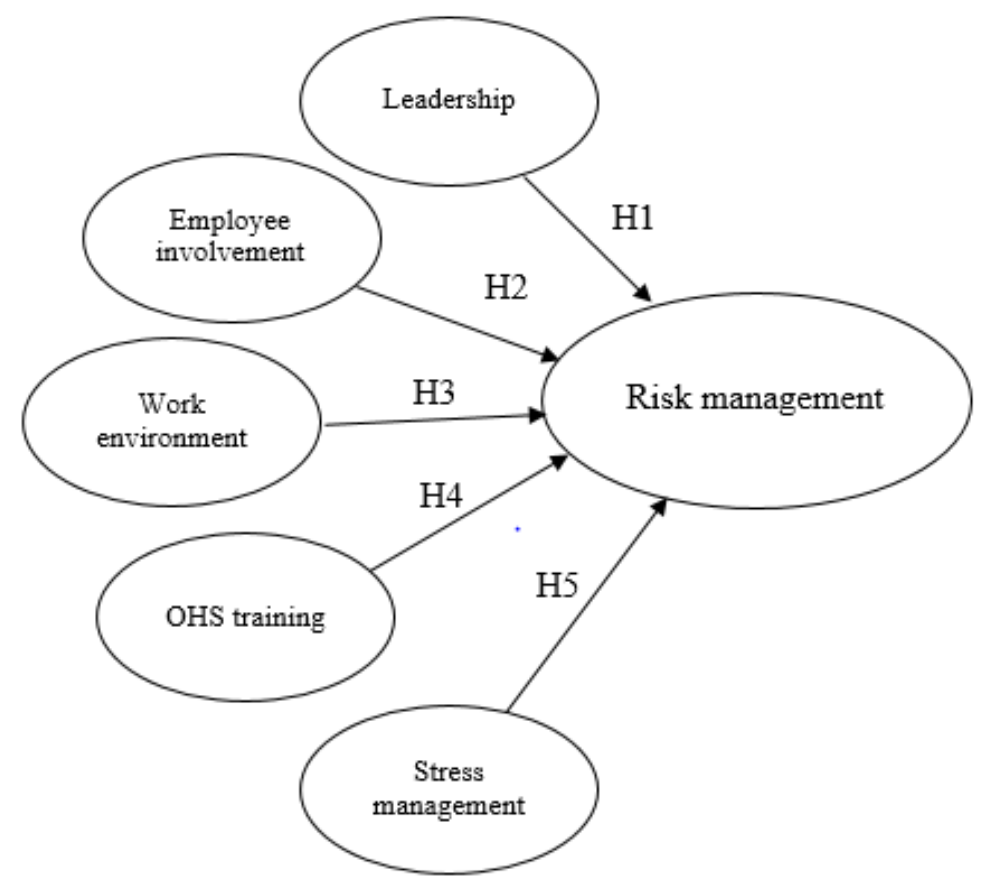

Fig. 1. Research framework

In the paper, we used the regression analysis, which is one of the most widely used techniques for analysing multifactor data. Its broad appeal and usefulness result from the conceptually logical process of using an equation to express the relationship between variable of interest and a set of related predictor variables.

Correlation coefficients between these dimensions should indicate the level of constructs influence on "Risk management", which is a desired outcome. The influence of each stated construct on "Risk management" is examined in the following paragraphs and analysed thoroughly. 


\section{Research results}

Delivered R2 (0.84) implies adequate relationship between predictors and "Risk management". Analysis show that OHS training, among other model constructs, has the greatest positive influence on "Risk management"; the delivered value of the significant path coefficient for this construct is below 0.005 . The hypothesis $\mathrm{H} 2(\mathrm{p}=0.145), \mathrm{H} 3(\mathrm{p}=0.008)$ and $\mathrm{H} 4(\mathrm{p}=0.016)$, with their path coefficients, suggest that changes in these predictors are not associated with changes in the response variable. (Fig. 2.)

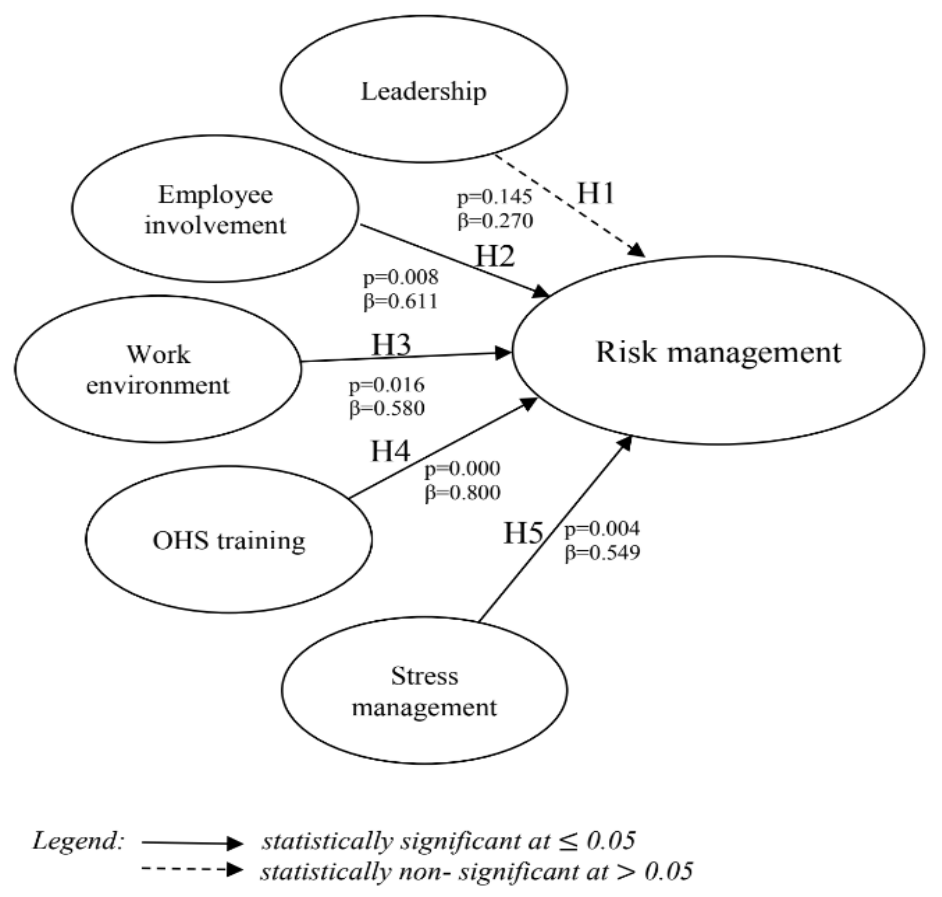

Fig. 2. First model

Regression Equation for First model:

Risk management

$$
\begin{aligned}
& =-4,81+0,270 \text { Leadership }+0,611 \text { Employee involvement }+0,580 \text { Work environment } \\
& +0,800 \text { OHS training }+0,549 \text { Stress management }(1)
\end{aligned}
$$

In further results we can see that the variance inflation factor (VIF) for leadership is equal to 3.72 which shows us the consistency of this construct and based on this we decide not to reject it.

Based on the results, for the construct "Employee involvement", the VIF is equal to 3.14 and for the "Work environment" is 4.85 , respectfully. This implies that these constructs should be merged into one. To confirm this, the correlation analysis was performed (Table 2).

\begin{tabular}{|l|l|l|l|}
\hline & Leadership & Employee involvement & Work environment \\
\hline Leadership & 1 & & \\
\hline Employee involvement & 0,783 & 1 & \\
\hline Work environment & 0,788 & 0,747 & 1 \\
\hline
\end{tabular}

Table 2. The Pearson correlation coefficients

The roles of leadership in employee involvement can be seen through the need for motivation of employees in need of active participation in activities such as decision making, project planning, risk management and others. Without the right support and guidance through the engagement process, employees may feel left out or unsure of the importance of their opinions. We decided to merge the following two constructs:

1. Leadership

2. Employee involvement

Taking in consideration a new formed predictor - leadership and employee involvement, along with the other predictors: work environment, OHS training and stress management another linear regression was performed. Delivered 
R2 (0.82) implies improved relationship between predictors and Risk management, in contrast to the previous model. Also, the proposed solution for the research model shows significant decreasement of constructs' VIF's. In the new analysis we focus our attention on variance inflation factor (VIF) and see that VIF is lower for every construct. VIF for leadership and employee involvement is 2.22 , and for work environment is 4.76 .

The final, adopted, solution of the research model shows the persistent significance of the OHS training. It has the greatest positive influence on risk management. Subsequently, the new formed construct leadership and employee involvement has the value $\mathrm{H} 1, \mathrm{p}=0.005$.

The final model and the significant path coefficients are shown in Fig. 3., as well as the beta coefficients for the constructs.

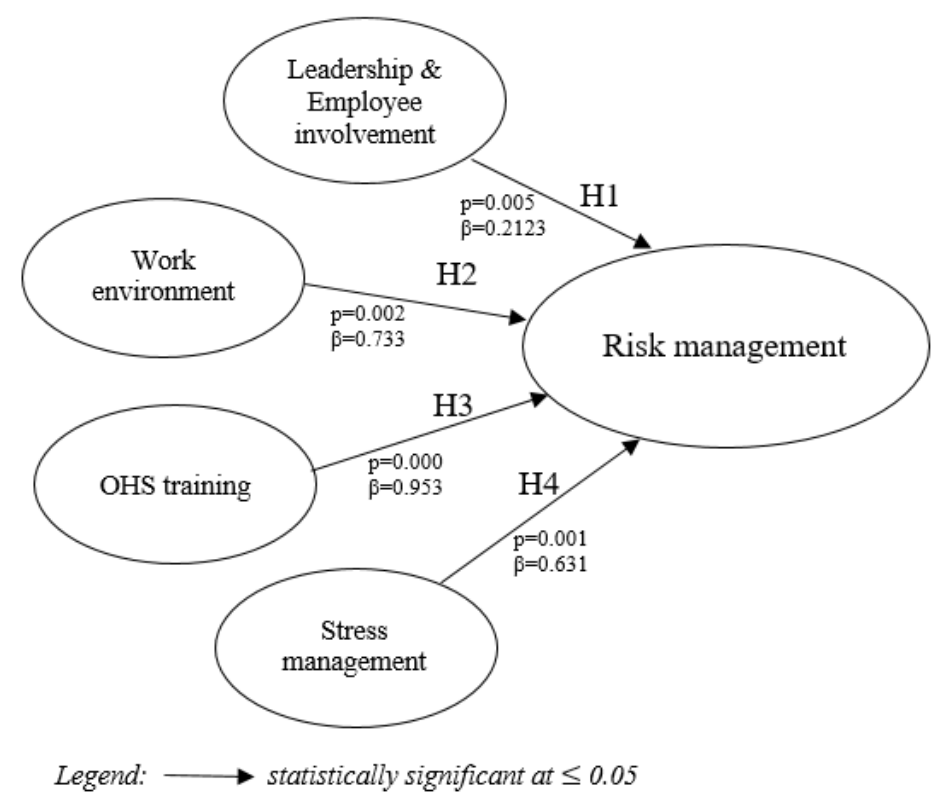

Fig. 3. Final Model

Regression Equation for Final model:

Risk management $=-4,62+$ 0,2123 Leadership \& Employee involvement + 0,733 Work environment + 0,953 OHS training $+0,631$ Stress management (2)

To assess the validity of the research model, in addition to afore-mentioned criteria, the distribution of residuals was also checked. Fig. 3 shows that the assumptions regarding the normal distribution of regression analysis residuals are met. Therefore, it could be said that residuals are distributed randomly and that there are no system errors (Fig. 4).

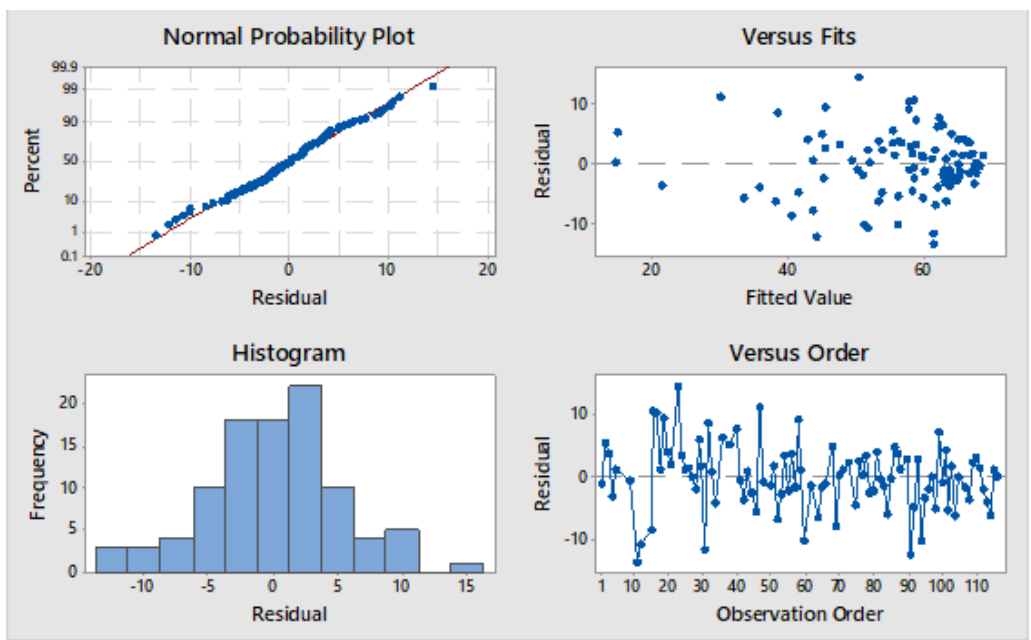

Fig. 4. Residual plots for risk management 


\section{Discussion}

Leadership actively takes accountability for the effectiveness of the risk management system. Leadership is about establishing, implementing and maintaining an OH\&S policy. This includes a commitment to provide safe and healthy working conditions which include risk management [24]. With this said, hypothesis H1 - "Leadership and employee involvement" is positively related to "Risk management" has been confirmed.

Work-related illnesses are very common and employees themselves should be a part of the influence on improvement of workplace health and safety, throughout the risk management [20], [25], which confirms hypothesis H2 - "Work environment" is positively related to "Risk management".

The organisation shall determine the necessary competence of workers that affects or can affect its OH\&S performance. Further, it should be ensured that workers are competent (including the ability to identify hazards) on the basis of appropriate education, training or experience [26]. The more skilled are the workers, the less chance there is for incidents and unexpected situations to happen. Some scientific studies highlighted a strong support for the effectiveness of training on worker OHS attitudes and beliefs [27]. According to these findings, hypothesis H3 - "OHS training" is positively related to "Risk management" is confirmed.

We come to the conclusion, throughout the literature, that occupational stress is a major cause of chronic and longterm illnesses with different levels of stress [28]. This is all highly dependent on demographic and occupational factors. [29]. Stress can even influence on the progress of management standard implementation reduced efficiency, decreased capacity to perform, dampened initiative and reduced interest in working, increased rigidity of thought, a lack of concern for the organisation and colleagues, and a loss of responsibility [29], [30], [31], [32]. Thus, Hypothesis H4 - "Stress management" is positively related to "Risk management" is confirmed.

\section{Conclusion}

As it is analysed through the paper, risk management is of great importance in every organisation. The focus is on preventive actions for unwanted situations and incidents. The paper confirmed that by focusing on training we can influence the most elimination of risks, or if the risk cannot be eliminated, it must, at least, be minimized by certain measures. Trainings are of great importance, first and foremost, to develop the organisation's culture and employee awareness, so that they can participate, freely, in all activities and promotions. In future research, we propose that the focus is on examining methodologies for developing the consciousness and culture of the organisation in order to develop motivation for training employees in aspect of OHS\&S.

\section{References}

[1] Rundmo, T., Hale, A., 2003. Managers' attitudes towards safety and accident prevention. Safety Science 41, 557574.

[2] DeJoy, D.M., Schaffer, B.S., Wilson, M.G., Vandenberg, R.J., Butts, M.M., 2004. Creating safer workplaces: assessing the determinants and role of safety climate. Journal of Safety Research 35, 81-90.

[3] Fernández-Muñiz, B., Montes-Peón, J.M., Vázquez-Ordás, C.J., 2007. Safety Culture: analysis of the causal relationships between its key dimensions. Journal ofSafety Research 38, 627-641.

[4] Fernández-Muñiz, B., Montes-Peón, J. M. and Vázquez- Ordás, C. J. (2009) 'Relation between occupational safety management and firm performance', Safety Science. Elsevier Ltd, 47(7), pp. 980-991. doi: 10.1016/j.ssci.2008.10.022.

[5] Vulanović, S., Delić, M., Ćosić, I., Žižakov, M., \& Vasić, S. (1848). Influence of occupational stress on organisanalzational performance, Technical Gazette, 2019, ISS 1330-3651, DOI: 10.17559/TV-20190602145208.

[6] Cadieux, J., Roy, M. and Desmarais, L. (2006) 'A preliminary validation of a new measure of occupational health and safety', Journal of Safety Research, 37(4), pp. 413-419. doi: 10.1016/j.jsr.2006.04.008

[7] Sinelnikov, S., Inouye, J. and Kerper, S. (2015) 'Using leading indicators to measure occupational health and safety performan-ce', Safety Science. Elsevier Ltd, 72, pp. 240- 248. doi: 10.1016/j.ssci.2014.09.010

[8] Podgórski, D. (2015) 'Measuring operational performance of OSH management system - A demonstration of AHP based selection of leading key performance indicators', Safety Science. Elsevier Ltd, 73, pp. 146-166. doi: 10.1016/j.ssci.2014.11.018.

[9] Fernández-Muñiz, B., Montes-Peón, J. M., \& Vázquez-Ordás, C. J. (2009). Relation between occupational safety management and firm performance. Safety Science, 47(7), 980-991. https://doi.org/10.1016/j.ssci.2008.10.022

[10] Sanjay L. Ahire, DamodarY.Golhar, M. A. W. (1996) 'Development and Validation of Tqm Constructs.', Decision sciences journal, 27(1), p. 2004. doi: 10.1111/j.1540- 5915.1996.tb00842.x.

[11] Tarí, J. J., Molina, J. F. and Castejón, J. L. (2007) 'The relationship between quality management practices and their effects on quality outcomes', European Journal of Operational Research, 183(2), pp. 483-501. doi: 10.1016/j.ejor.2006.10.016. 
[12] Pečujlija, M. et al. (2011) 'Leadership and productivity in transition: Employees' view in Serbia', Journal of East European Management Studies, 16(3), pp. 251-263.

[13] Perdomo - Ortiz, J., Gonzalez-Benito, J., Galende, J., 2006. Total quality management as a forerunner of business innovation capability. Technovation 26, 1170-1185.

[14] Manders, B., Vries, H. J. De, \& Blind, K. (2015). Technovation ISO 9001 and product innovation : A literature review and research framework. Technovation, 1-15. https://doi.org/10.1016/j.technovation.2015.11.004

[15] Mosadeghrad, A. M., \& Yarmohammadian, M. (2006). A study of relationship between managers' leadership style and employees' job satisfaction The Future studies of Normal Delivery Promotion in Iran View project Inequalities in utilization of health services among older people in Iran View project. Article in Leadership in Health Services, (April). https://doi.org/10.1108/13660750610665008

[16] Edem, M., Akpan, E., \& Pepple, N. (2017). Impact of Workplace Environment on Health Workers. Occupational Medicine \& Health Affairs, 05(02), 1-5. https://doi.org/10.4172/2329-6879.1000261

[17] Zakon o bezbednosti i zdravlju na radu (2005). Available at: http://www.minrzs.gov.rs/cir/dokumenti/bezbednost-izdravlje-na-radu/zakoni, 10.7.2019.

[18] Aleksić, A. et al. (2009) Bezbednost i zdravlje na radu. Monograph. Novi Sad, Serbia.

[19] Smith, A.(2000).The scale of perceived occupational stress. Journal of Occupational Medicine, 50(5):294-98.

[20] Hedge, A. et al. (1989) 'Work-related illness in offices: A proposed model of the "sick building syndrome", Environment International, 15(1-6), pp. 143-158. doi: 10.1016/0160-4120(89)90020-2.

[21] Marcatto, F. et al. (2016) 'Work-related stress risk factors and health outcomes in public sector employees', Safety Science. Elsevier Ltd, 89, pp. 274-278. doi: 10.1016/j.ssci.2016.07.003.

[22] Lehto, M. R., \& Cook, B. T. (2012). Occupational Health and Safety Management. Handbook of Human Factors and Ergonomics: Fourth Edition, 699-733. https://doi.org/10.1002/9781118131350.ch25

[23] Fernández, F. B., \& Pérez, M. Á. S. (2015). Analysis and modeling of new and emerging occupational risks in the context of advanced manufacturing processes. Procedia Engineering, 100(January), 1150-1159. https://doi.org/10.1016/j.proeng.2015.01.478

[24] ISO Organisation. (2018). ISO 45001:2018, Occupational health and safety management systems - Requirements with guidance for use.

[25] Walters David, N. T. (2007) Worker Representation and Workplace Health and Safety. Palgrave Macmillan, London. doi: 10.1057/9780230210714.

[26] Randall, R., Nielsen, K. and Tvedt, S. D. (2009) 'The development of five scales to measure employees' appraisals of organisational-level stress management interventions', Work and Stress, 23(1), pp. 1-23. doi: 10.1080/02678370902815277.

[27] Ricci, F. et al. (2016) 'Effectiveness of occupational health and safety training: A systematic review with metaanalysis', Journal of Workplace Learning, 28(6), pp. 355-377. doi: 10.1108/JWL-11-2015-0087.

[28] Brookes, K., Limbert, C., Deacy, C., O’Reilly, A., Scott, S., \& Thirlaway, K. (2013). Systematic review: Workrelated stress and the HSE management standards. Occupational Medicine, 63(7), $463-472$. https://doi.org/10.1093/occmed/kqt078

[29] Mellor, N. et al. (2011) "Management Standards" and workrelated stress in Great Britain: Progress on their implementation', Safety Science. Elsevier Ltd, 49(7), pp. 1040-1046. doi: 10.1016/j.ssci.2011.01.010.

[30] Wellens, B. T. and Smith, A. P. (2006) 'Combined workplace stressors and their relationship with mood, physiology, and performance', Work and Stress, 20(3), pp. 245-258. doi: 10.1080/02678370601022712.

[31] Glasscock, D. J. et al. (2006) 'Psychosocial factors and safety behaviour as predictors of accidental work injuries in farming', Work and Stress, 20(2), pp. 173-189. doi: 10.1080/02678370600879724.

[32] Fairbrother, K. \& Warn, J. (2003). Workplace dimension: Stress and Job satisfaction. J. Management Psychol, $18(1), 8-21$.

[33] Nunnally, J., and Bernstein, H. (1994) Psychometric theory.New York: McGraw-Hill Inc.

[34] Kremljak, Z. \& Kafol, C. (2014) Types of Risk in a System Engineering Environment and Software Tools for Risk Analysis, Procedia Engineering 69, pp 177-183. doi: 10.1016/j.proeng.2014.02.218. 